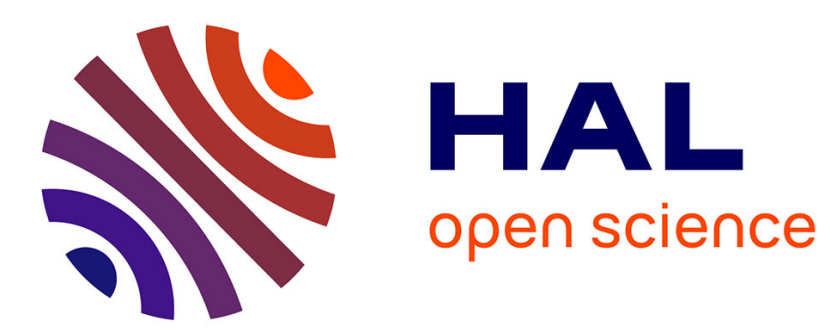

\title{
Spatial distribution of nucleated bubbles in molten glasses undergoing coalescence and growth
}

Damien Boloré, Franck Pigeonneau

\section{To cite this version:}

Damien Boloré, Franck Pigeonneau. Spatial distribution of nucleated bubbles in molten glasses undergoing coalescence and growth. Journal of the American Ceramic Society, 2018, 101 (5), pp.1892-1905. 10.1111/jace.15361. hal-01646137

HAL Id: hal-01646137

https://hal-mines-paristech.archives-ouvertes.fr/hal-01646137

Submitted on 23 Nov 2017

HAL is a multi-disciplinary open access archive for the deposit and dissemination of scientific research documents, whether they are published or not. The documents may come from teaching and research institutions in France or abroad, or from public or private research centers.
L'archive ouverte pluridisciplinaire HAL, est destinée au dépôt et à la diffusion de documents scientifiques de niveau recherche, publiés ou non, émanant des établissements d'enseignement et de recherche français ou étrangers, des laboratoires publics ou privés. 


\title{
Spatial distribution of nucleated bubbles in molten glasses undergoing coalescence and growth*
}

\author{
Damien Boloré ${ }^{1}$ and Franck Pigeonneau ${ }^{2 \dagger}$ \\ ${ }^{1}$ Surface du verre et Interfaces, 39 quai L. Lefranc, \\ 93303 Aubervilliers cedex, France \\ ${ }^{2}$ MINES ParisTech, PSL Research University, \\ CEMEF - Centre de mise en forme des matériaux, \\ CNRS UMR 7635, CS 10207, Claude Daunesse \\ 06904 Sophia Antipolis cedex, France
}

November 23, 2017

\begin{abstract}
2D spatial distributions and growths of nucleated bubbles during the re-melting of glass samples are experimentally investigated. To follow the bubble population undergoing coalescence, the temporal behavior of the Voronoï tessellation built by the bubble positions are monitored. During coalescence, the Voronoï cell areas are fitted by a single-parameter Gamma distribution. Numerical time simulation of population of bubbles undergoing coalescence shows an exponential increase of the parameter associated to the Gamma distribution with the fraction of coalesced bubbles in agreement with experimental observation. An initial density of nuclei is then estimated; direct observation would require an extremely high space resolution. The bubble number density is two orders of magnitude larger on the side which was in contact with tin bath than on the other side in contact with atmosphere. Moreover, bubbles grow faster on tin side. From a thermodynamic and mass transfer models, we prove that tin reduces the glass former liquid which leads to an increase of dissolved sulfur explaining the more abundant bubble population and the enhanced growth rate on tin side.
\end{abstract}

\section{Introduction}

Bubble nucleation is the object of intensive research since the pioneer contribution of Volmer [1] and is still investigated both experimentally and theoretically $[2,3]$. It has been reported that the classical theory fails to predict the bubble nucleation rate by 20 orders of magnitude in binary liquids [4]. According to Lubetkin [5], three types of bubble nucleation are enumerated. The first is due to a pressure decrease under vapor pressure in a pure liquid (cavitation). The second involves an increase of temperature also in a pure medium (boiling) [6] and the last nucleation process occurs when gases are dissolved in a medium. The change of conditions of pressure, temperature or even chemical reactions shifts the gas solubility, leading to bubble nucleation. This last type of nucleation is involved for instance in carbonated beverages [7], volcanic eruptions [8] or industrial glass production [9].

\footnotetext{
* accepted for publication in J. Am. Ceram. Soc.

$\dagger$ Corresponding author: franck.pigeonneau@mines-paristech.fr
} 
It is usually admitted that the nucleation occurs when the supersaturation, corresponding to the ratio of the amount of dissolved gas in the bulk to the amount in saturated conditions, overtakes a threshold. Moreover, thermodynamically, the Gibbs energy decreases when the nuclei size is larger than a critical value. Mainly, two modes of nucleation prevail. If nuclei appear everywhere in the bulk, the nucleation is considered as homogeneous. This kind of nucleation has been studied for instance in volcanology $[10,8]$ due to the depressurization of natural silicate liquids. When nuclei are created in presence of impurities, the nucleation is designated as heterogeneous. The energy barrier in the homogeneous nucleation is higher than in the heterogeneous nucleation leading to a larger supersaturation to initialize the nucleation [5]. Other modes of nucleation have been also proposed by Jones et al. [11] involving supersaturations close to unity. According to these authors, this mode occurs when pre-existing bubbles or cavities are present.

The understanding of bubble nucleation is of particular interest in glass industry since bubbles are the main defect in the final product. In glass melting, various gas species are involved in the process. While $\mathrm{CO}_{2}, \mathrm{~N}_{2}$ and $\mathrm{H}_{2} \mathrm{O}$ come from raw materials and atmosphere above the glass bath during the melting process, $\mathrm{SO}_{2}$ and $\mathrm{O}_{2}$ are due to fining agent used to inflate bubbles [12]. The bubble removal called "fining process" needs very high temperature $\left(\sim 1500^{\circ} \mathrm{C}\right)$ to ensure that the final melt is completely homogeneous $[13,14,15,9]$. Understanding the bubble formation would provide clues to prevent or control these bubbles, allowing industrial glassmakers to decrease the furnace temperature thus extending the lifetime of it. This is increasingly true since the proportion of glass cullet in raw materials will be increased to reduce $\mathrm{CO}_{2}$ release. Despite the reduced $\mathrm{CO}_{2}$ content, the density of nucleated bubbles stays important. Consequently, the main objective of this current work is to explain this paradoxical observation.

More accurately, the purpose of the current article is to determine the magnitude of bubble number density at the first stage of nucleation when a glass is remelted. We want to know the thermodynamic conditions of nucleation and the consequence on the bubble growth. In-situ observation has been chosen to study bubble nucleation. It is very efficient because other properties of glass do not change much during the nucleation process [16, 17, 18]. We investigate a particular glass coming from the float process in which the glass sheet floats on a tin bath while the other side is in contact with $\mathrm{N}_{2} / \mathrm{H}_{2}$ atmosphere.

The article consists of two parts. Firstly, in-situ observations will be presented and analyzed and secondly, thermodynamic and mass transfer models will be used to explain observations. Section 2 details the experimental method to melt glasses and to perform the image analysis. Results and discussion are presented in the third section. The thermodynamic and the mass transfer models are presented and used in section 4. Finally, we draw few conclusions in the last section.

\section{Materials and methods}

\section{$2.1 \quad$ Experimental set-up}

A schematic diagram of the experimental apparatus is shown in Figure 1-(a). A laboratory furnace equipped with a silica glass window is used to monitor the melting process of soda-lime-silicate glass (window glass) at relatively low temperatures (from $700^{\circ} \mathrm{C}$ to $1100^{\circ} \mathrm{C}$ ). Two cameras, having spatial resolutions of 60 and $25 \mu \mathrm{m}$ /pixel, respectively, record events occurring during the melting. Due to radiation, the light is emitted by the heated material itself and by the surrounding furnace. The black background is a view of the cold bottom and the bubbles diffuse light, enabling a good contrast between glass and bubbles. Thus, we have access to the projection of the crucible, meaning that we cannot directly know on which side the bubbles are located. To overcome this uncertainty, we can slightly rotate the crucible. The projection also implies that some objects may be partially hidden at the beginning of the melting process but they usually appear when bubbles start to move. Figure 1 depicts four snapshots at different times and four temperatures in the melting process. The 

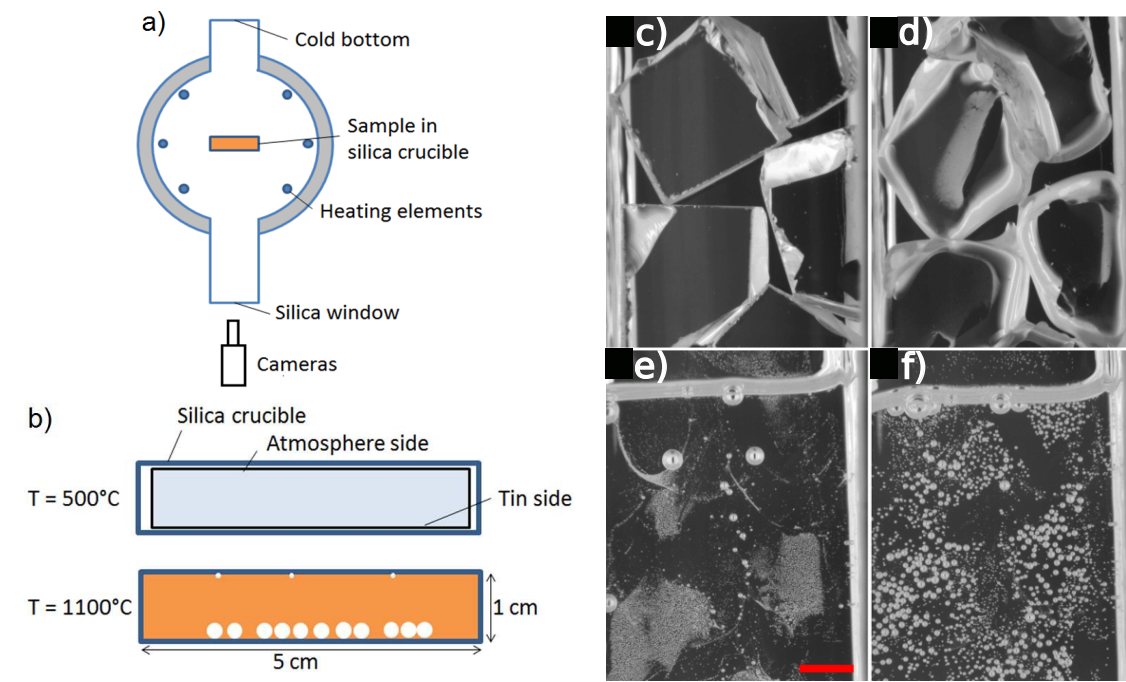

Figure 1: Schematic description of the experimental setup: (a) view of the furnace and (b) crucible. Views of the crucible during the re-melting of float glass at four temperatures: (c) $T=500^{\circ} \mathrm{C}$. (d): $T=800^{\circ} \mathrm{C}$. (e): $T=1050^{\circ} \mathrm{C}$. (f): $T=1100^{\circ} \mathrm{C}(t=5000 \mathrm{~s})$. Scale bar is $1 \mathrm{~cm}$.

\begin{tabular}{lrrrrrrrr}
\hline Oxide & $\mathrm{SiO}_{2}$ & $\mathrm{CaO}$ & $\mathrm{Na}_{2} \mathrm{O}$ & $\mathrm{MgO}$ & $\mathrm{Al}_{2} \mathrm{O}_{3}$ & $\mathrm{FeO}$ & $\mathrm{Fe}_{2} \mathrm{O}_{3}$ & $\mathrm{SO}_{3}$ \\
\hline wt \% & 72.4 & 8.88 & 13.85 & 3.74 & 0.73 & 0.014 & 0.055 & 0.22 \\
\hline
\end{tabular}

Table 1: Composition of the glass samples.

initial situation observed at $T=500^{\circ} \mathrm{C}$ is provided in Figure $1-(\mathrm{c})$. At $T=800^{\circ} \mathrm{C}$, Figure $1-(\mathrm{d})$, the glass begins to flow as the temperature increases. At $T=1050^{\circ} \mathrm{C}$, white areas, constituted of very small bubbles, appear. Finally in Figure 1-(e) obtained at $T=1100^{\circ} \mathrm{C}$, densely-packed bubbles have coalesced and rise in the crucible. Bubbles on the other face of the crucible become visible at $T=1100^{\circ} \mathrm{C}$.

\subsection{Materials}

The glass samples have two thicknesses: 4 and $10 \mathrm{~mm}$ with the same chemistry, reported in Table 1 . It is noteworthy that samples have been forming by the float process in which the glass is spread on a tin bath. During this operation, tin diffuses into the glass matrix while the glass interface in contact with atmosphere mainly composed by a $\mathrm{N}_{2} / \mathrm{H}_{2}$ mixing does not experience the tin contact. Various studies tackle the effect of tin migration on the glass structure [19,20,21, 22] and its properties, mainly mechanical and optical [23, 24]. At the end of the forming process, a glass sheet is heterogeneous in composition, i.e. on "tin side", the glass is enriched with tin oxides while on "atmosphere side", tin is practically absent.

Before the introduction into the vitreous silica crucible, samples are cleaned and dried by air flow. They stay one night at $150^{\circ} \mathrm{C}$ before being heated up to $800^{\circ} \mathrm{C}$ at $10^{\circ} \mathrm{C} / \mathrm{min}$. From $800^{\circ} \mathrm{C}$ to $1100^{\circ} \mathrm{C}$, the temperature is raised at $3^{\circ} \mathrm{C} / \mathrm{min}$ and then maintained at $1100^{\circ} \mathrm{C}$ for few hours. In the following, we set the reference time when $T=1100^{\circ} \mathrm{C}$ is reached. Hence, positive times correspond to the spent time at $1100^{\circ} \mathrm{C}$ when negative times correspond to the time during the temperature ramp: $T(t=-6000 \mathrm{~s})=800^{\circ} \mathrm{C}, T(t=-3000 \mathrm{~s})=950^{\circ} \mathrm{C}$ for instance. Temperature in the furnace is very homogeneous. Indeed at $1100^{\circ} \mathrm{C}$, the measurements of several thermocouples indicate that 

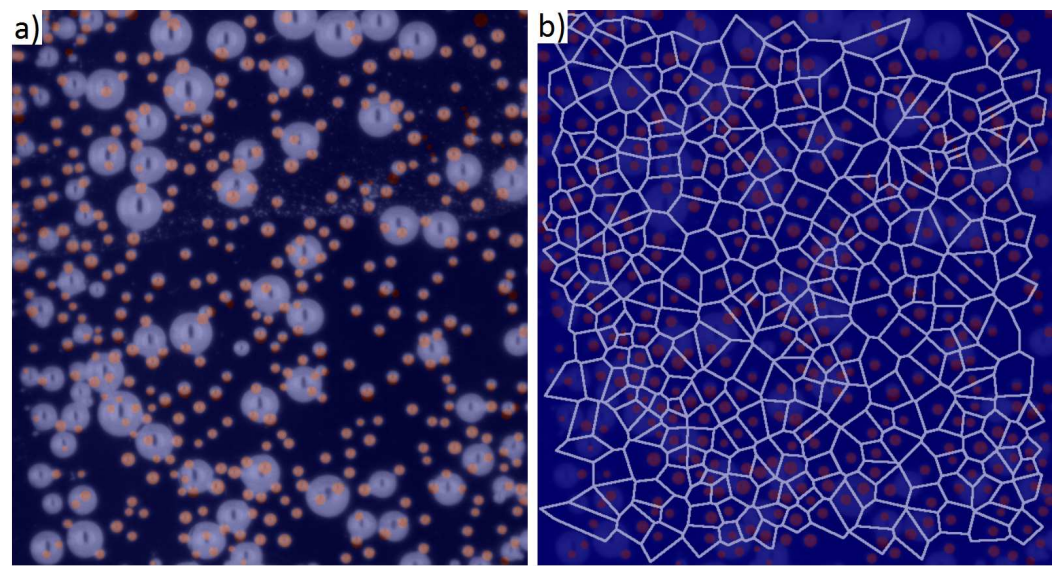

Figure 2: Detection of bubbles on atmosphere side of the glass (a) and Voronoï tessellation for the same image (b).

the maximum difference is $3^{\circ} \mathrm{C}$ in the space domain where the crucible with glass sample is localized.

Samples are inserted into the crucible so that only two interfaces exist.

\subsection{Image analysis methods}

Custom-made image analysis software in Python is used to measure the number and size of bubbles. The segmentation of each image is performed using two methods of thresholding from the Python library [25]: an Otsu threshold and an adaptive threshold. The bubbles are detected on the binarized images using a watershed process. The eccentricity of the detected objects is studied to be sure to select only single bubbles. The results are then manually checked. To evaluate its accuracy a set of testing images has been generated on which the algorithm is tested. The test images are generated to have the same histogram than experimental images and with similar numbers of simulated bubbles. The relative error is $5 \%$ maximum and even less when radii are larger than $100 \mu \mathrm{m}$. In some cases, when the automation does not give reliable results, typically for bubble diameters close to three pixels, a manual measurement is performed.

To study the bubbles spatial distribution and its dynamics, we follow the technique employed by Lhuissier et al. [26] and Xu et al. [27] based on the determination of the Voronoï tessellation providing us a local measurement of the bubble number density. The PyVoro library is used to perform the Voronoï tessellation. We do not consider Voronoï cells on the edges of the images to avoid boundary-effects. Figure 2 shows the detection of bubbles on the left of the figure and the Voronoï tessellation on the right. The bubbles are partially hidden by others bubbles located on tin side and their detection is made over several images. In Figure 2-(b), only cells which do not interact with the edges of the image are considered.

From the image analysis software, bubbles size is determined to obtain the bubble growth rate. An average is then performed to have an overall growth rate. In order to be sure about this measurement, we perform manually the detection and the size on few isolated bubbles (around twenty objects have been taken). Results obtained by the two methods are very similar.

\section{$3 \quad$ Experimental analysis}

The phenomenon described here takes place at the interface between the crucible and molten glass but is also observed at the interface between two melted glass sheets. Observations and related 

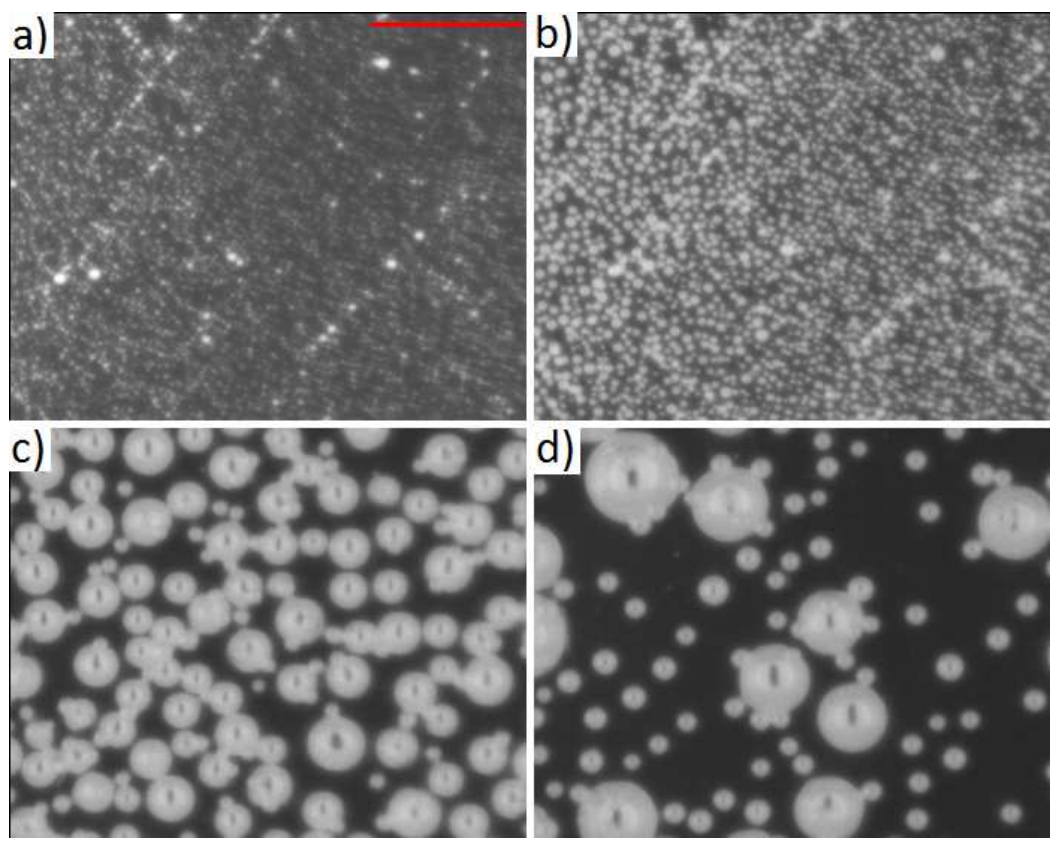

Figure 3: Zoomed views of the bubble population at different times and temperatures: (a) $T=$ $1050^{\circ} \mathrm{C}$, (b) $T=1080^{\circ} \mathrm{C}$, (c) $T=1100^{\circ} \mathrm{C}(t=1500 \mathrm{~s})$ and $(\mathrm{d}) \mathrm{T}=1100^{\circ} \mathrm{C}(t=5000 \mathrm{~s})$. Scale bar is $2.5 \mathrm{~mm}$.

measurements are easy to perform when one of the materials is solid, we will thus report only these experiments but the conclusions remain true in a general case. One of the main differences between the two situations is the motion of the bubbles: in our case, the bubbles being nucleated on a rigid and immobile interface, they stay pinned longer than when they are generated between two glass sheets. The composition of the generated bubbles and its measurement are beyond the scope of the present study. It will be addressed in the next section with the numerical method to study the bubble dynamics.

On both sides of a glass sheet bubbles become measurable at the same temperature of $1050^{\circ} \mathrm{C}$ as it can be seen in Figure 3-(a). Indeed, bubbles only appear on areas where the glass/crucible contact is established. These events occur around a temperature equal to $800^{\circ} \mathrm{C}$. On tin side, the location of the bubbles is strongly influenced by the history of the glass flow as it is clearly shown in Figure 1-(d) and Figure 1-(e). Figure 3 shows the evolution of the bubble population in one of these dense areas during one experiment. We do not observe this phenomenon on atmosphere side where bubbles are more homogeneously nucleated. Figure 3 -(b) observed at $T=1080^{\circ} \mathrm{C}$ shows that bubbles grow leading to the coalescence process to start. There is still no visible motion, except when bubbles coalesce. Bubbles on tin side can now be easily distinguished from the others in Figure 3-(c). Finally, at the end of the observation depicted in Figure 3-(d), bubbles rise on tin side.

The densities of bubbles on tin and atmosphere side exhibit a strong difference as illustrated on Figure 4. Indeed, bubbles located on tin side coalesce and the bubble number density decreases quasi-exponentially with time while its remains constant on atmosphere side. Measurements are not possible in the blue area due to the camera resolution. The data (circle) located at $t=-5000$ $\mathrm{s}$ is extrapolated as it will be explained in more detail below. 


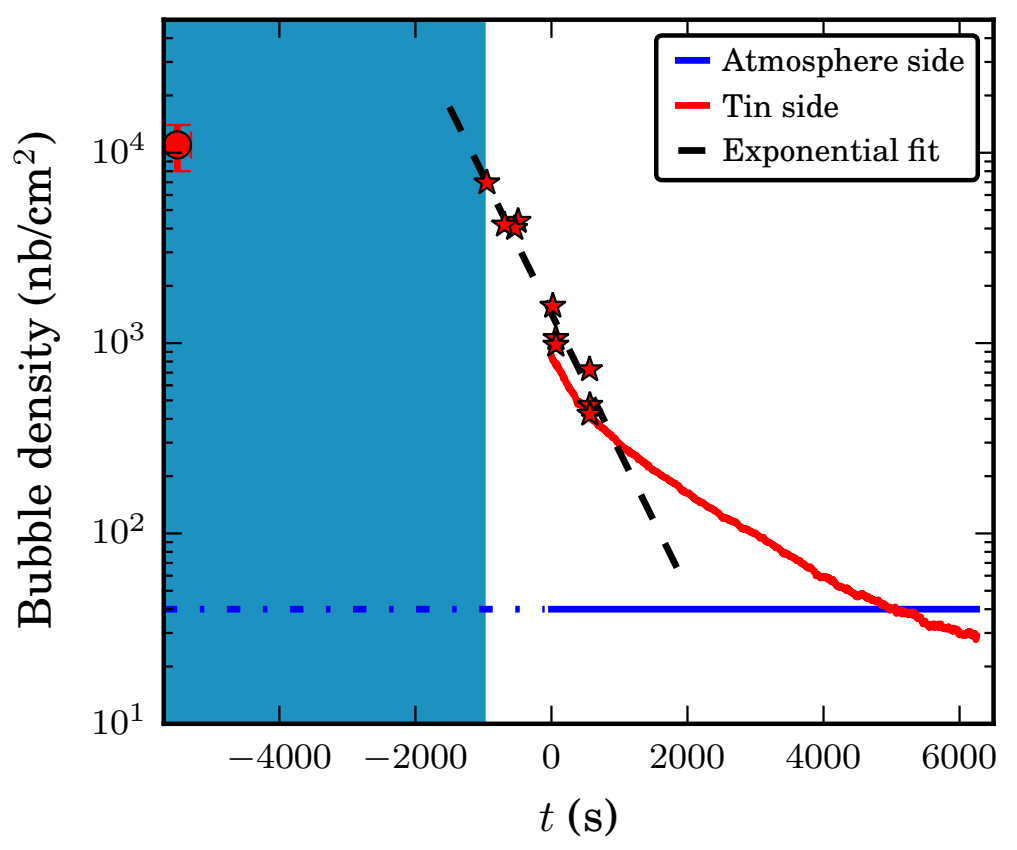

Figure 4: Automatic (lines) and manual measurements (stars) of bubble density on both sides of float glass.

\subsection{Bubbles on atmosphere side}

The population of bubbles on atmosphere side does not change significantly during the experiment. The bubble number density is 40 bubbles $/ \mathrm{cm} 2$ at a temperature of $1050^{\circ} \mathrm{C}$. Since bubbles are isolated, this value is considered equal to the nucleon number density during the nucleation process. To study the spatial distribution of these bubbles, we perform Voronoï tessellation. The probability density function (pdf) of the normalized area of Voronoï cells is plotted in Figure 5. Ferenc and Néda [28] showed that this size-distribution follows a Gamma-distribution given by the following relation:

$$
f_{\Gamma}(y, n)=\frac{n^{n}}{\Gamma(n)} y^{n-1} \exp (-n y)
$$

for which $\Gamma$ is the gamma function, $y$ is the normalized Voronoï cell area, i.e. $A /\langle A\rangle$ and $n$ the order parameter. When objects are randomly distributed over a surface (particular case of Poisson Voronoï Diagrams) the parameter $n$ is equal to $7 / 2$.

In first approximation, bubbles on atmosphere side can be considered randomly distributed. It implies that the nucleation process at the interface between glass and the crucible follows a Poisson process. The particular case of Poisson-Voronoï Diagrams appears when the nuclei are randomly distributed and uncorrelated, which happen in a large number of situations $[29,30,31,26]$. The deviation observed for small cells and large cells may indicate the presence of clusters as observed in particle-laden flows [32]. The physical reason for the presence of these bubble clusters is still to be determined. 


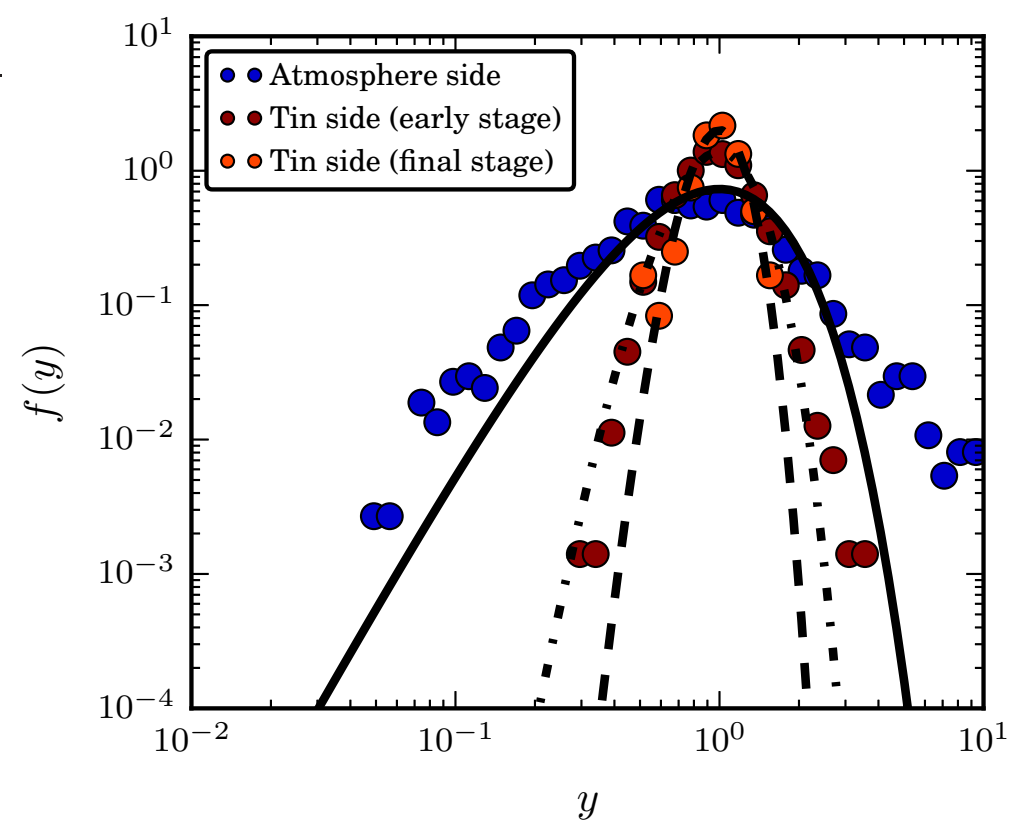

Figure 5: Experimental size-distributions $f(y)$ of normalized Voronoï cells area $(y=A /\langle A\rangle)$ for both sides at $1050^{\circ} \mathrm{C}(t=-1000 \mathrm{~s})$ and for tin side at $1100^{\circ} \mathrm{C}(t=1500 \mathrm{~s})$.

\subsection{Bubbles on tin side}

Bubbles on tin side are densely packed and their assemblies have well-defined shapes as it is showed in Figure 1-(e). In the following, we focus our analysis on these areas where the bubble number density is quite homogeneous. At a temperature of $1050^{\circ} \mathrm{C}$, the bubble number density is around 4000 bubbles $/ \mathrm{cm}^{2}$. This value is two orders of magnitude larger than the estimation obtained on atmosphere side. Bubbles on tin side coalesce from the beginning to the end of the fusion process as they are close to each other. Figure 4 shows the behavior of the density on tin side. Between $t=-1000 \mathrm{~s}$ and $t=1500 \mathrm{~s}$, the bubble number density decreases exponentially with time, i.e. $\sim \exp (-t / \tau)$, for which the characteristic time $\tau$ is estimated at $600 \mathrm{~s}$. After $t=1500 \mathrm{~s}$, bubbles on tin side begin to move and the coalescence process is slowed.

Figure 5 shows the probability density function of the normalized area of the Voronoï cells $A /\langle A\rangle$ on tin side at a temperature of $1050^{\circ} \mathrm{C}$ and $1100^{\circ} \mathrm{C}(t=1500 \mathrm{~s})$. At $1050^{\circ} \mathrm{C}$, the overall distribution is narrowed around the mean compared with the atmosphere side. By setting the order parameter of the Gamma-distribution to 12.2 , it is possible to fit the obtained distribution. The distribution at $T=1100^{\circ} \mathrm{C}$ is narrowed again around the mean and can also be fitted by a Gamma-distribution with $n=25.5$. The parameter for the Gamma-distribution is taken equal to $7 / 2$ for atmosphere side corresponding to the case of random spatial distribution. Consequently, the measured population is not randomly distributed on tin side because the parameter $n$ is not equal to $7 / 2$. The comparison between the two curves measured on tin side at different times shows that the coalescence process has a strong impact on the spatial distribution of bubbles.

\subsection{Bubble size growth}

By recording the time behavior of bubble population with the image analysis software, the average radius of isolated bubbles as a function of time, both on tin and atmosphere sides of molten glass 


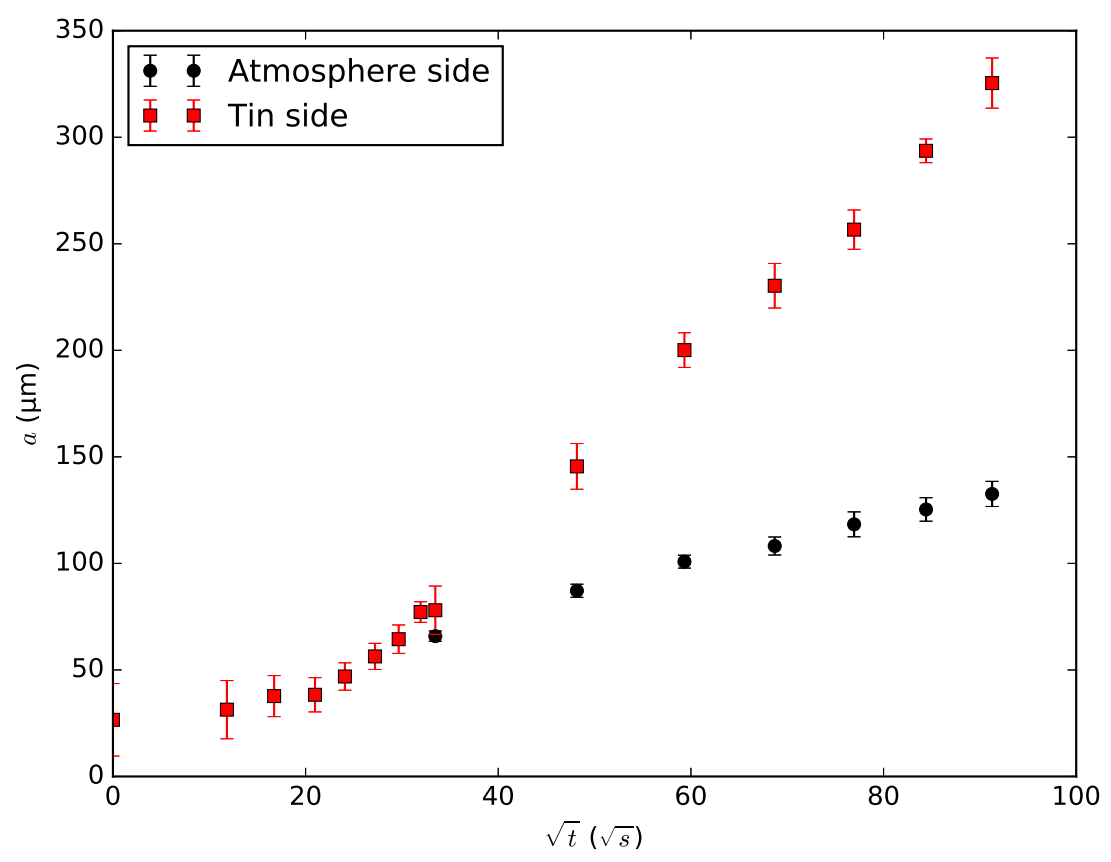

Figure 6: Radius $a(\mu \mathrm{m})$ as a function of the square root of time $\sqrt{t}(\sqrt{\mathrm{s}})$ for bubbles on tin and atmosphere sides of molten glass samples.

samples, is determined. Due to the large bubble number density on tin side, the early recording corresponds uniquely to the tin side. Figure 6 plots the average bubble radius a as a function of square root of time. Both on tin and atmosphere sides bubble radius increases with the square root of time. This means that the growth should be driven by mass transfer from dissolved gases in the liquid to bubbles. In the case of Oswald ripening, it is expected that inclusions grow as a function of time at the power one third [33]. This trend is not observed in our experiments. This result also means that the permeabilities of gases dissolved in the molten glass are not high enough to have a growth dynamics due to the Ostwald ripening. In fact, apart from water vapor which has a high permeability, the other gases are not permeable enough to promote the ripening.

On tin side, two regimes of growth are observed: a first one with a slow growth rate and a second regime for which bubbles grow more quickly. On atmosphere side, even if the two regimes exist the difference on the growth rate is reduced. Clearly, in the second regime, the growth rate on tin side is larger than on atmosphere side. At the end of the observation, the radius is three times larger for bubbles on tin side than for bubbles on atmosphere side. This observation underlines that the mass transfer is more efficient on tin side, meaning that the quantity of dissolved gases is more important on tin side.

\subsection{Influence of coalescence on spatial repartition}

According to the main conclusions of the results given above, we assume that immediately after the nucleation, nuclei on tin side should also be randomly distributed (same situation as on atmosphere side). However, the nuclei being close enough, they coalesce before we can measure the spatial distribution at $1050^{\circ} \mathrm{C}$. This means that the spatial distribution firstly measured is the result of a history.

Therefore we perform a geometrical simulation of the coalescence process for bubbles on tin side 


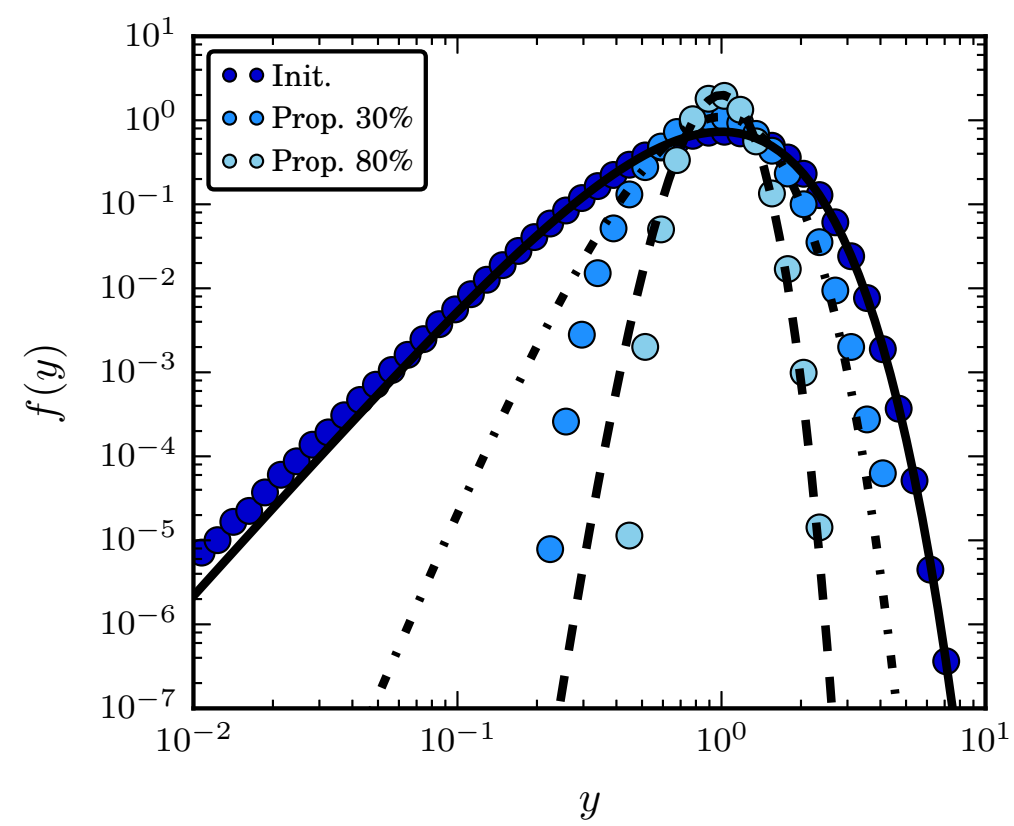

Figure 7: Simulated size-distributions of normalized Voronoï cell areas for three situations: initial situation and after the coalescence of $30 \%$ and $80 \%$ of the objects.

that are submitted to coalescence during their growth. The numerical simulation of the coalescence process is geometrical. We consider a population of $N$ points, which positions are Poissondistributed (i.e., random and uncorrelated process) on a virtual square image of $10^{8}$ pixels. We then consider the two closest neighbors and merge them. The resulting point is located at the barycenter of the two previous points. After the merging, the population is then composed of $N-1$ points. The process is repeated until the desired number of coalescences is reached. We achieve this calculation for $N=1000,3000,5000$ and 10000 points to check that mean size of Voronoï cells area does not affect the resulting distributions. For each set of points, we perform coalescence events to have between 16 to $95 \%$ of coalesced bubbles. We obtained the simulation data by evolving more than $2.8 \cdot 10^{7}$ bubbles. This number decreases when the coalescence occurs (down to $10^{6}$ bubbles for the situation with $95 \%$ of coalesced bubbles), but our sample size remains sufficiently large to determine the order parameter with a good confidence.

Figure 7 shows the behavior of the distribution shape for three situations: initial population randomly distributed, after the coalescence of $30 \%$ and $80 \%$ of the objects. The corresponding fitted distributions are also shown. Similarly to Ferenc and Néda [28], we decide to keep a one-parameter Gamma-distribution for the fitting. This choice is supported by the process of coalescence itself. Indeed, according to Smoluchowski [34], the random interaction between two populations results in a convolution process on the size-distribution leading to the distribution of Eq. (1). Gamma distribution is also reported to be involved in fragmentation or aggregation processes with varying parameter [35, 36].

If $d_{0}$ and $d$ are the initial and current bubble number densities respectively, the proportion of coalesced bubbles is defined as follows

$$
x=\frac{d-d_{0}}{d_{0}} .
$$

The evolution of the parameter $n$ when varying the proportion of coalesced objects is plotted on 


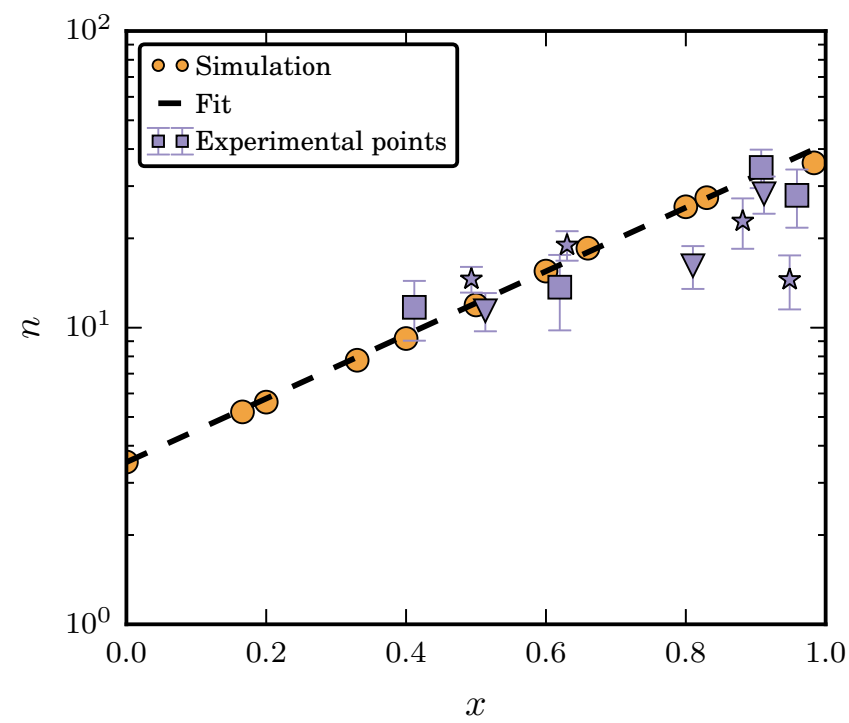

Figure 8: Parameter $n$ of the Gamma-distribution versus the proportion of coalesced objects $x$.

Figure 8 . The data from the simulation can be fitted by the equation:

$$
n=\frac{7}{2} \exp (2.47 x)
$$

Consequently, the proportion of coalesced objects is estimated by building the Voronoï tessellation and fitting the size-distribution of the resulting cells. For even higher proportions of coalesced objects, we can predict that the distributions will tend to a normal distribution, as a consequence of the Central Limit Theorem. This is already taken into account in our approach, as it is well-known that the Gamma-distribution of high order tends asymptotically when $n$ is large to the normal distribution written as follows:

$$
f_{\Gamma}(y, n) \underset{\text { large }}{\sim} \mathcal{N}\left(y, \frac{n-1}{n}, \frac{n-1}{n^{2}}\right),
$$

for which the second and the third parameters are the mean and the variance respectively. The asymptotic case when $n$ goes to infinity correspond to the Dirac distribution centered on the normalized cell equal to one.

\subsection{Initial densities of nuclei on both sides of float glass}

Bubbles do not interact with each other during the experiment on atmosphere side of float glass, thus the situation is obvious. The nucleation process occurs with a low intensity (around 40 bubbles $/ \mathrm{cm}^{2}$ ), resulting in a sparse population of bubbles, which grow isolated. As the distribution of the normalized cells area is fitted by a Gamma-distribution of parameter $7 / 2$, we can conclude that the nucleation follows a Poisson process, which is reported to take place in various situations.

On tin side of float glass, the situation is more complex. The flow history of the glass leads to some areas where bubbles are very densely packed. We measure the distribution of the normalized Voronoï cells area and the corresponding density. Fitting the resulting distributions with a Gammadistribution and plotting the evolution of the fit parameter leads to the experimental data points 
on Figure 8. The dashed line is calculated with Eq. (3). Experimental points represent behaviors for three different experiments under the same conditions. The three symbols correspond to three experiments achieved under the same conditions.

In order to minimize the difference between experimental results and simulations, we adjust $d_{0}$ with the least square method as shown in Figure 8. By this way, an approximate initial density of nuclei is estimated equal to $d_{0}=9300 \pm 500 \mathrm{nuclei} / \mathrm{cm}^{2}$ for all experiments on tin side. The deviations observed at large proportion of coalesced objects may be due to several facts. First, our geometrical model does not take into account the actual size of the bubbles: as the nucleation process occurs, the size distribution of bubbles shows a wider dispersion that creates a significant difference between our simulation and the real situation. Secondly, when the bubbles grow, they begin to move. It means that the spatial repartition will be more and more distorted as the experience continues. At some point, it becomes impossible to define a spatial repartition of moving bubbles.

However, in the range of $x \in[0.4 ; 0.8]$, the evolution of our experimental points is in good agreement with the simulation. In summary, what we measured on tin side around $1050^{\circ} \mathrm{C}$ is the image of the evolution of randomly distributed nuclei, approximately half of whom have coalesced before the measurement was even possible. Thus, the nucleation on tin side is more than 230 times more intense than on atmosphere side.

\section{Thermodynamic and mass transfer models}

Following the experimental results provided above, the glass composition plays an important role on the nucleation and on the bubble number density. Even if the tin amount is small, bubble nucleation and growth are strongly affected. To understand such effects, we need to estimate the gas solubilities to have access to the supersaturation. Thus, we use a model taking into account the oxidation-reduction reactions important to describe the chemically dissolved species as $\mathrm{SO}_{2}$ and $\mathrm{O}_{2}$. Moreover, bubble growths are relevant data to know more accurately the driving forces corresponding to the gradient of concentrations between the bulk and the bubble interface. In the following, the supersaturation in the case of liquid undergoing nucleation due to dissolved gases is recalled. After, the thermodynamic and mass transfer models will be presented and used to compare with experimental results.

\subsection{Supersaturation of dissolved gases}

In the classical theory of nucleation, the critical radius of nuclei arises from the balance between the increase of surface energy and the decrease of volumetric enthalpy. In the case of multispecies dissolved in a liquid, the easiest way to introduce the critical radius over which a nucleus exists is to consider that the pressure inside the nucleus must be larger than the pressure in the liquid. Using the Laplace relation, the critical radius for which a bubble can exist is obviously given by:

$$
a_{\mathrm{cr}}=\frac{2 \gamma}{\left(\sum_{i=1}^{N_{g}} S a_{\mathrm{G}_{i}}^{1 / \beta_{\mathrm{G}_{i}}}-1\right) P_{l}}
$$

with $\gamma$ the surface tension between the molten glass and the bubble atmosphere, $P_{l}$ is the pressure in the liquid around the bubble taking into account the hydrostatic pressure if it is needed. Here, $N_{g}$ dissolved species are considered for which the saturation $S a_{\mathrm{G}_{i}}$ is defined by the relation [37]

$$
S a_{\mathrm{G}_{i}}=\frac{C_{\mathrm{G}_{i}}}{L_{\mathrm{G}_{i}} P_{l}^{\beta_{\mathrm{G}_{i}}}} .
$$


In the last equation, the molar concentration $C_{\mathrm{G}_{i}}$ of the gas species $\mathrm{G}_{i}$ has been related to the partial pressure of the species $\mathrm{G}_{i}$ in the bubble using Henry's law as follows:

$$
C_{\mathrm{G}_{i}}=L_{\mathrm{G}_{i}} P_{\mathrm{G}_{i}}^{\beta_{\mathrm{G}_{i}}}
$$

for which $L_{\mathrm{G}_{i}}$ is the Henry coefficient depending on temperature, chemical reactions and glass composition. The exponent $\beta_{\mathrm{G}_{i}}$ takes into account that the molar concentration is not necessary proportional to the partial pressure. For species which are physically dissolved, the linearity is generally true. But for water, for instance, it is currently admitted that the molar concentration is proportional to the square root of the partial pressure of the water vapor due to the fact that water is chemically dissolved [38].

From Eq. (5), the supersaturation when $\mathrm{Ng}$ species are dissolved in a liquid is then defined by

$$
\sigma=\sum_{i=1}^{N_{g}} S a_{\mathrm{G}_{i}}^{1 / \beta_{\mathrm{G}_{i}}}-1 .
$$

From the knowledge of molar concentrations and Henry coefficients, each saturation degrees $S a_{\mathrm{G}_{i}}$ can be determined as a function of temperature. Usually, Henry coefficients are given by

$$
L_{\mathrm{G}_{i}}=A_{\mathrm{G}_{i}} e^{B_{\mathrm{G}_{i}} / T},
$$

with $A_{\mathrm{G}_{i}}$ and $B_{\mathrm{G}_{i}}$ two coefficients depending on the glass composition which can be found in $[39,14]$.

Consequently, to determine the supersaturation as a function of the temperature and chemical conditions of the liquid, the molar concentrations of dissolved gases are required. As already mentioned above, dissolved gas species are shared between fining species like $\mathrm{SO}_{2}$ and $\mathrm{O}_{2}$ involved in the oxidation-reduction reactions and non-fining gas species like $\mathrm{CO}_{2}, \mathrm{~N}_{2}$ and $\mathrm{H}_{2} \mathrm{O}$.

\subsection{Thermodynamic equilibrium}

The thermodynamic equilibrium is determined following the model developed by Pigeonneau [40]. Considering a generic element $M$ with two degrees of oxidation $n+k$ and $n$, the equilibrium is expressed as follows:

$$
\mathrm{M}^{(n+k)+}+\frac{k}{2} \mathrm{O}^{2-} \rightleftharpoons \mathrm{M}^{n+}+\frac{k}{4} \mathrm{O}_{2} .
$$

Using Henry's law, Eq. (7), the oxygen pressure is replaced by the molar concentration of dissolved oxygen. Consequently, the temperature-dependent equilibrium constant of this reaction is given by:

$$
K_{\mathrm{M}^{(n+k)+/ n+}}=\frac{C_{\mathrm{M}^{n+}} C_{\mathrm{O}_{2}}^{k / 4}}{C_{\mathrm{M}^{(n+k)+}}} .
$$

In our case, given the polyvalent elements (Fe, $\mathrm{Sn}$ and $\mathrm{S}$ ) present in the melt, we consider the following redox pairs: $\mathrm{Fe}^{3+} / \mathrm{Fe}^{2+}, \mathrm{Sn}^{4+} / \mathrm{Sn}^{2+}, \mathrm{S}^{6+} / \mathrm{S}^{4+}$ and $\mathrm{S}^{4+} / \mathrm{S}^{2-}$. These redox pairs are often considered to be involved in the tin penetration mechanism [19, 20, 22] as well as in the fining process [41, 42]. According to Müller-Simon [41], the dissolved form of $\mathrm{SO}_{2}$ is admitted to be given by the cation $\mathrm{S}^{4+}$. The fining gas species, $\mathrm{O}_{2}$ and $\mathrm{SO}_{2}$ are then determined by the thermodynamic equilibrium of the oxidation-reduction reactions.

The enthalpy and entropy of each reaction are taken from data provided in [42] obtained by voltammetric measurements. The partial pressure $P_{\mathrm{O}_{2}}$ corresponds to the pressure in the atmospheric gas phase in equilibrium with the molten glass. This quantity does not make sense in molten glass not interacting with an atmosphere. Nevertheless, using an electrochemical oxygen sensor, the "equilibrium" partial pressure of $\mathrm{O}_{2}$ can be determined [43, chap. 3]. 
Assuming that $R$ reactions take place in the melt with $N_{I}$ ionic species and $N_{f g}$ fining gas species, the generic reaction $r$ is given by

$$
\sum_{i=1}^{N_{I}} \nu_{r i}^{\prime} \mathrm{A}_{i}+\sum_{j=1}^{N_{f g}} \beta_{r j}^{\prime} \mathrm{G}_{j} \rightleftharpoons \sum_{i=1}^{N_{I}} \nu_{r i}^{\prime \prime} \mathrm{A}_{i}+\sum_{j=1}^{N_{f g}} \beta_{r j}^{\prime \prime} \mathrm{G}_{j} .
$$

$\mathrm{A}_{i}$ is the ion $i \in\left[1 ; N_{I}\right]$ and $\mathrm{G}_{j}$ corresponds to the gas species $j \in\left[1 ; N_{f g}\right]$. The stoichiometric coefficients for ionic and gas species taken into account in reaction $r$ are defined by the following relations [44]:

$$
\begin{gathered}
\nu_{r i}=\nu_{r i}^{\prime \prime}-\nu_{r i}^{\prime}, \text { for } i=1 \text { to } N_{I} . \\
\beta_{r j}=\beta_{r j}^{\prime \prime}-\beta_{r j}^{\prime}, \text { for } j=1 \text { to } N_{f g} .
\end{gathered}
$$

The equilibrium constant of reaction $r$ is given by [44]

$$
K_{r}=\prod_{i=1}^{N_{I}} C_{\mathrm{A}_{i}}^{\nu_{r i}} \prod_{j=1}^{N_{f g}} C_{\mathrm{G}_{j}}^{\beta_{r j}}=\exp \left(\frac{-\Delta G_{r}}{\mathcal{R} T}\right),
$$

where $\Delta G_{r}$ is the Gibbs free energy of reaction $r$ defined by

$$
\Delta G_{r}=\Delta H_{r}-T \Delta S_{r}
$$

with $\Delta H_{r}$ and $\Delta S_{r}$ the enthalpy and entropy of reaction $r$ respectively.

The determination of ionic and gaseous concentrations is carried out by setting the chemical affinity equal to zero for each of the $R$ reactions. This equilibrium is determined using a Newton method to find all concentrations as a function of the temperature. In this procedure, a reference state is needed and it will be found by comparison with experimental data.

\subsection{Mass transfer model}

As already mentioned above, dissolved gas species are considered corresponding to non-fining gases $\left(\mathrm{N}_{2}, \mathrm{CO}_{2}\right.$ or $\left.\mathrm{H}_{2} \mathrm{O}\right)$ and fining gas species, $\mathrm{O}_{2}$ and $\mathrm{SO}_{2}$. Assuming that in the particular case addressed in this work the liquid motion does not play a significant role on the mass transfer, the number of moles of gas species $\mathrm{G}_{j}$ can be determined by

$$
\frac{d n_{\mathrm{G}_{j}}}{d t}=4 \pi a D_{\mathrm{G}_{j}}\left(C_{\mathrm{G}_{j}}-L_{\mathrm{G}_{j}} P_{\mathrm{G}_{j}}^{\beta_{\mathrm{G}_{j}}}\right),
$$

where $n_{\mathrm{G}_{j}}$ is the number of moles of gas species $\mathrm{G}_{j}, a$ the bubble radius, $D_{\mathrm{G}_{j}}$ the diffusion coefficient of dissolved species $\mathrm{G}_{j}, C_{\mathrm{G}_{j}}$ the bulk molar concentration far away from the bubble interface, and $P_{\mathrm{G}_{j}}$ the partial pressure of the species $\mathrm{G}_{j}$ in the bubble.

To determine the radius, the Rayleigh-Plesset equation is used for which the inertia contribution is neglected. In this case, the temporal derivative of the radius is commonly given by [45]:

$$
\frac{d a}{d t}=\frac{a}{4 \mu}\left(\sum_{i=1}^{N_{g}} P_{\mathrm{G}_{i}}-P_{l}-\frac{2 \gamma}{a}\right) .
$$

A routine written in Python has been developed to determine as a function of time the number of moles of gas species $\mathrm{G}_{j}$ and the bubble radius $a$. 


\begin{tabular}{|c|cccc|}
\hline Reaction & $\mathrm{Fe}^{3+/ 2+}$ & $\mathrm{Sn}^{4+/ 2+}$ & $\mathrm{S}^{6+/ 4+}$ & $\mathrm{S}^{4+/ 2-}$ \\
\hline$\Delta H_{r}\left(\mathrm{~kJ} \cdot \mathrm{mol}^{-1}\right)$ & 117 & 209 & 262.6 & 602.7 \\
$\Delta S_{r}\left(\mathrm{~J} \cdot \mathrm{mol}^{-1} \cdot \mathrm{K}^{-1}\right)$ & 47.43 & 92.30 & 135.84 & 182.44 \\
\hline
\end{tabular}

Table 2: Enthalpy and entropy of reactions used for the numerical computations according to Müller-Simon [42].

\begin{tabular}{|c|ccccc|}
\hline Species & $\mathrm{O}_{2}$ & $\mathrm{SO}_{2}$ & $\mathrm{CO}_{2}$ & $\mathrm{~N}_{2}$ & $\mathrm{H}_{2} \mathrm{O}$ \\
\hline$A_{\mathrm{G}_{i}}\left(\mathrm{~mol} \cdot \mathrm{m}^{-3} \cdot \mathrm{Pa}^{\left.\beta_{\mathrm{G}}\right)}\right.$ & $1.37 \cdot 10^{-4}$ & $6.44 \cdot 10^{-7}$ & $5.6 \cdot 10^{-7}$ & $1.1 \cdot 10^{-5}$ & $6.8 \cdot 10^{-1}$ \\
$B_{\mathrm{G}_{i}}(\mathrm{~K})$ & -6633 & 7860 & 3120 & -6633. & -613 \\
\hline
\end{tabular}

Table 3: Values of $A_{\mathrm{G}_{i}}$ and $B_{\mathrm{G}_{i}}$ used to compute the Henry coefficient given by eq. (9) according to [14].

\subsection{Numerical results and comparison with experiments}

The numerical simulations have been used in order to estimate redox conditions in the two situations: without and with tin presence. The composition of the bulk glass (i.e. not considering tin) is given in Table 1. On the tin side, the mass fraction of tin is taken equal to $0.15 \mathrm{wt} \%$.

The molar concentrations of non-fining species are difficult to know accurately. However, it is possible to estimate their molar concentrations assuming that glass is in equilibrium with atmosphere experimented by the glass during the melting process. Since float glass is melted in general in flame furnace, the atmosphere above the glass bath is mainly composed of $73 \%$ of nitrogen, $9 \%$ of $\mathrm{CO}_{2}$ and $8 \%$ of water vapor for a combustion between $\mathrm{CH}_{4}$ and air. If solubilities of non-fining species are used at a temperature of reference taken here at $1473.15 \mathrm{~K}, C_{\mathrm{CO}_{2}}$ is equal to 0.04 $\mathrm{mol} / \mathrm{m}^{3}, C_{\mathrm{N}_{2}}$ at $0.01 \mathrm{~mol} / \mathrm{m}^{3}$ and $C_{\mathrm{H}_{2} \mathrm{O}}$ at $40 \mathrm{~mol} / \mathrm{m}^{3}$. These values are close to the data given by Beerkens [14].

The numerical values of the enthalpy and entropy of reaction in Table 2 have been taken from data obtained by Müller-Simon [42]. Equilibrium constants are written with the molar concentration of $\mathrm{O}_{2}$. Consequently, the values of $\Delta H_{r}$ and $\Delta S_{r}$ provided in Table 2 take into account the oxygen solubility.

The constants $A_{\mathrm{G}_{i}}$ and $B_{\mathrm{G}_{i}}$ to determine solubilities of the five gas species have been taken from Beerkens [14] for the pressure in $\mathrm{Pa}$ and the molar concentration in $\mathrm{mol} / \mathrm{m}^{3}$. Table 3 gathers values for the five gas species.

The diffusion coefficients of each species are determined as a function of temperature following the relation

$$
D_{\mathrm{G}_{i}}=A_{\mathrm{G}_{i}}^{\text {diff }} \exp \left(-\frac{B_{\mathrm{G}_{i}}^{\text {diff }}}{T}\right)
$$

for which $A_{\mathrm{G}_{i}}^{\text {diff }}$ and $B_{\mathrm{G}_{i}}^{\text {diff }}$ are provided in Table 4 .

To determine the temporal derivative of the bubble radius given by Eq. (17), the dynamic viscosity, the surface tension and the liquid pressure are required. The dynamic viscosity of the

\begin{tabular}{|c|ccccc|}
\hline Species & $\mathrm{O}_{2}$ & $\mathrm{SO}_{2}$ & $\mathrm{CO}_{2}$ & $\mathrm{~N}_{2}$ & $\mathrm{H}_{2} \mathrm{O}$ \\
\hline$A_{\mathrm{G}_{i}}^{\text {diff }}\left(\mathrm{m}^{2} \cdot \mathrm{s}^{-1}\right)$ & $4.2 \cdot 10^{-3}$ & $4.45 \cdot 10^{-7}$ & $1.92 \cdot 10^{-5}$ & $4.3 \cdot 10^{-5}$ & $1.2 \cdot 10^{-5}$ \\
$B_{\mathrm{G}_{i}}^{\text {diff }}(\mathrm{K})$ & 26646 & 15360 & 21516 & 19364 & 18320. \\
\hline
\end{tabular}

Table 4: Values of $A_{\mathrm{G}_{i}}$ and $B_{\mathrm{G}_{i}}$ used to compute the coefficient coefficient given by eq. (18) according to [14]. 


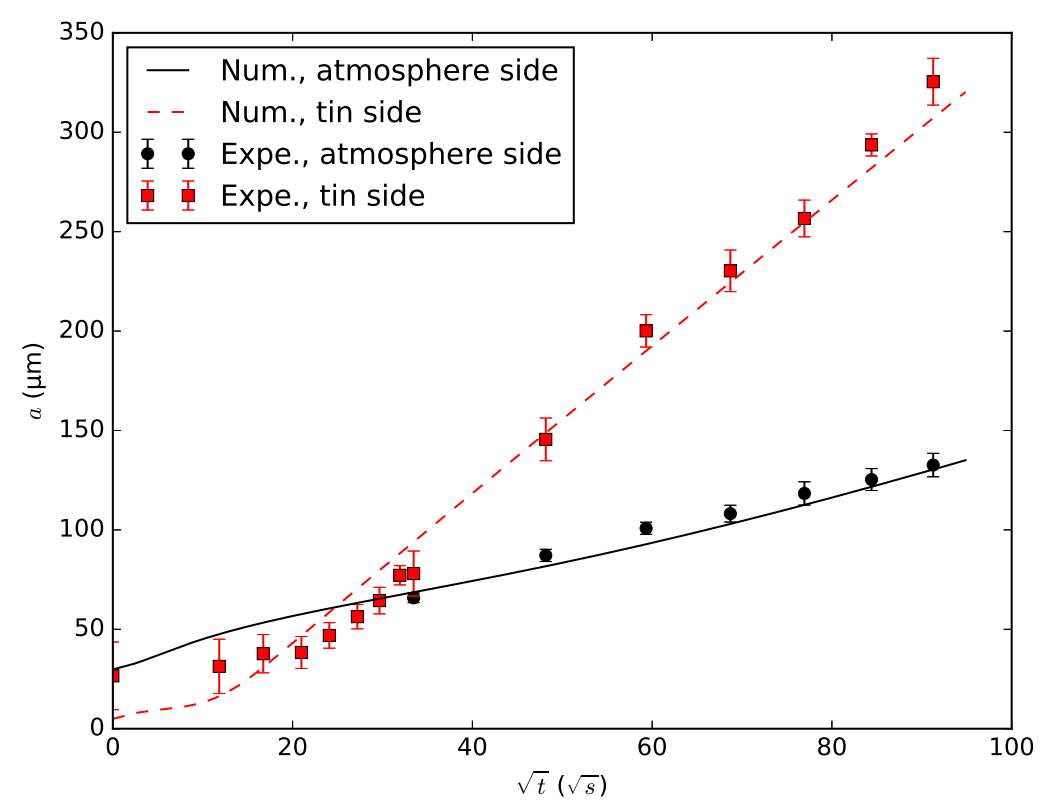

Figure 9: Bubble radius $a$ as a function of $\sqrt{t}$ obtained with the numerical model coupling the chemical equilibrium and the mass transfer models. Comparison with experimental data.

molten glass is written according to the Vogel-Fulcher-Tammann relation under the form

$$
\mu=\mu_{0} \exp \left(\frac{B_{\mu}}{T-T_{\mu}}\right)
$$

for which $\mu_{0}=1.95 \cdot 10^{-3} \mathrm{~Pa} \cdot \mathrm{s}, B_{\mu}=9855.06 \mathrm{~K}$ and $T_{\mu}=539.15 \mathrm{~K}$ corresponding to the window glass composition. The surface tension is taken equal to $\gamma=0.36 \mathrm{~N} / \mathrm{m}$. Finally, the liquid pressure is taken equal at one atmosphere: $P_{l}=101325 \mathrm{~Pa}$.

The redox states in glasses with and without tin must be defined. To do that, we determine the bubble size behaviors as a function of time by solving the mass transfer model and by changing the reference state to determine the amount of fining gas species. Initially, the bubble is assumed composed mainly with the weaker soluble gases, i.e. $\mathrm{CO}_{2}$ and $\mathrm{N}_{2}$ for which the molar fractions are taken equal to 0.9 and 0.1 respectively. The reference state of glasses has been taken at $T=1200^{\circ} \mathrm{C}$ for which the redox state can be adapted to set the equilibrium partial pressure of oxygen.

The numerical results are provided in Figure 9 for the tin and atmosphere faces. Only the experimental data obtained on tin side have been used to reproduce the bubble behavior at small and large times. On tin side, the initial bubble size has been taken equal to $5 \mu \mathrm{m}$. The redox state defined by the ratio

$$
N_{\text {red }}=\frac{C_{\mathrm{Fe}^{2+}}}{C_{\mathrm{Fe}^{2+}}+C_{\mathrm{Fe}^{3+}}}
$$

has been found equal to 0.196. By using the equilibrium constant of iron reaction and the solubility of oxygen, an equilibrium oxygen partial pressure equal to $4.13 \cdot 10^{-4}$ bar at $T=1200^{\circ} \mathrm{C}$.

With these conditions, behaviors of bubble growth at small and large times are well reproduced with our numerical model. First, the bubble radius behaves like a square root of time with the two regimes. For the atmosphere side, the initial radius is set equal to $30 \mu \mathrm{m}$. The redox state has been adapted to fit the experimental data at long time. At the reference temperature $T=1200^{\circ} \mathrm{C}$, 


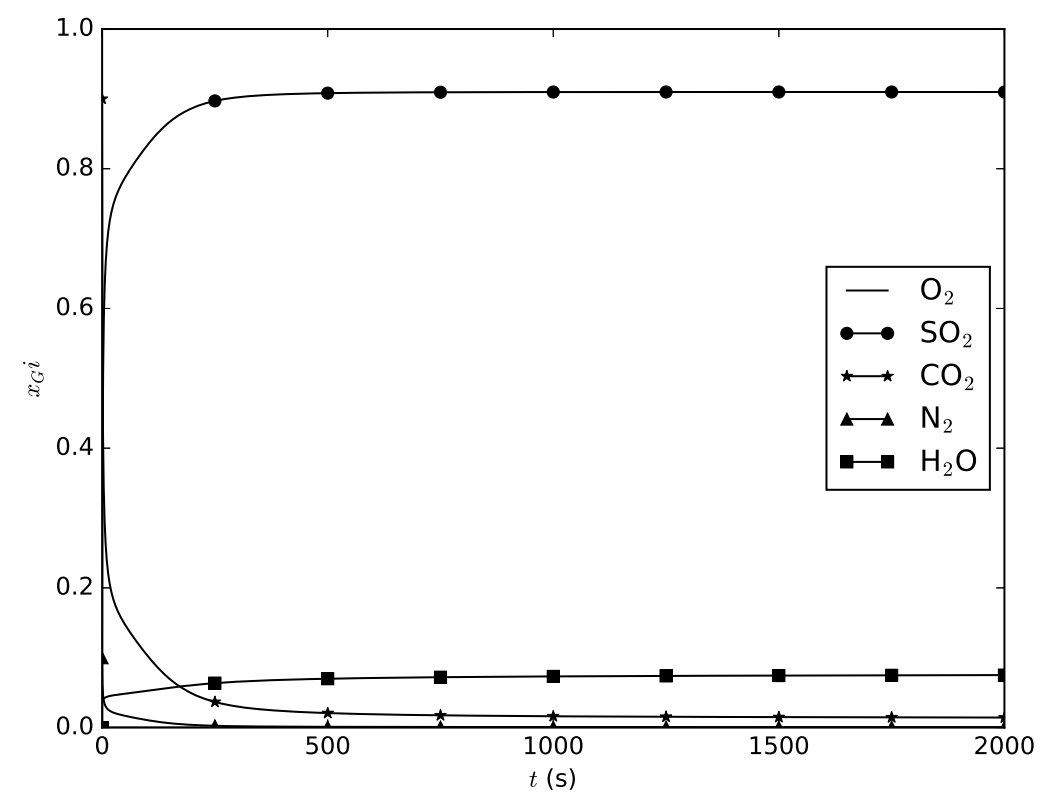

Figure 10: Molar fraction $x_{\mathrm{G}_{i}}$ of the five gas species in the bubble as a function of time obtained with the mass transfer model over the first hour for bubble on tin side.

the redox state is equal to 0.155 meaning that the glass is more oxidized without tin species. The corresponding oxygen pressure is equal to $1.29 \cdot 10^{-3}$ bar. This is in good agreement with observations made by Flank et al. [22] which state that tin side is more reduced than atmosphere side.

The increase of the bubble growth rate with tin is the consequence of the reduction of molten glass. Indeed, in such situation, the amount of dissolved $\mathrm{SO}_{2}$ under reduced conditions is more important. Consequently, the bubble growth is meanly driven by the mass transfer of $\mathrm{SO}_{2}$. In order to control this phenomenon, Figures 10 and 11 depict the molar fractions of each species in each bubble over the first half hour in the conditions of tin and atmosphere sides. In Figure 10 obtained for a bubble on tin face, a strong decrease of $\mathrm{CO}_{2}$ and $\mathrm{N}_{2}$ is observed in few seconds. For larger time, the decrease of $\mathrm{CO}_{2}$ is least while the molar fraction of $\mathrm{SO}_{2}$ increases with the same time scale. This behavior corresponds to the first regime observed on the bubble size evolution provided in Figure 9. In this regime, the mass transfer is driven by the release of $\mathrm{CO} 2$ from the interior of the bubble to the molten glass. In the second regime for which the bubble growth is faster, the mass transfer is driven by the mass transfer of $\mathrm{SO}_{2}$.

In the case of atmosphere side given in Figure 11, the decreases of $\mathrm{CO}_{2}$ and $\mathrm{N}_{2}$ are observed at smaller rates than in the tin side. The temporal behaviors of $\mathrm{SO}_{2}$ and $\mathrm{CO}_{2}$ change in opposite ways. Remark that after one hour the main compositions of each bubble are different between the two faces. On tin side, the bubble is mainly composed by $\mathrm{SO}_{2}$ and $\mathrm{H}_{2} \mathrm{O}$ while on atmosphere side, the bubble is composed by $\mathrm{SO}_{2}, \mathrm{CO}_{2}$ and $\mathrm{H}_{2} \mathrm{O}$.

From this numerical simulation and redox states adapted from the comparison with bubble growth behaviors, the saturation conditions on both faces can be determined as a function of the temperature. Figure 12 and Figure 13 present the saturations of the five gas species dissolved in the molten glass both on tin and atmosphere sides. Clearly, the glass reduction leads to an increase of the $\mathrm{S} 4+$ corresponding to the dissolved species of $\mathrm{SO}_{2}$. For $T>1050^{\circ} \mathrm{C}$, the $\mathrm{SO}_{2}$ saturation is larger than one and increases with the temperature to reach a value around 7 at $1600^{\circ} \mathrm{C}$. Saturations of 


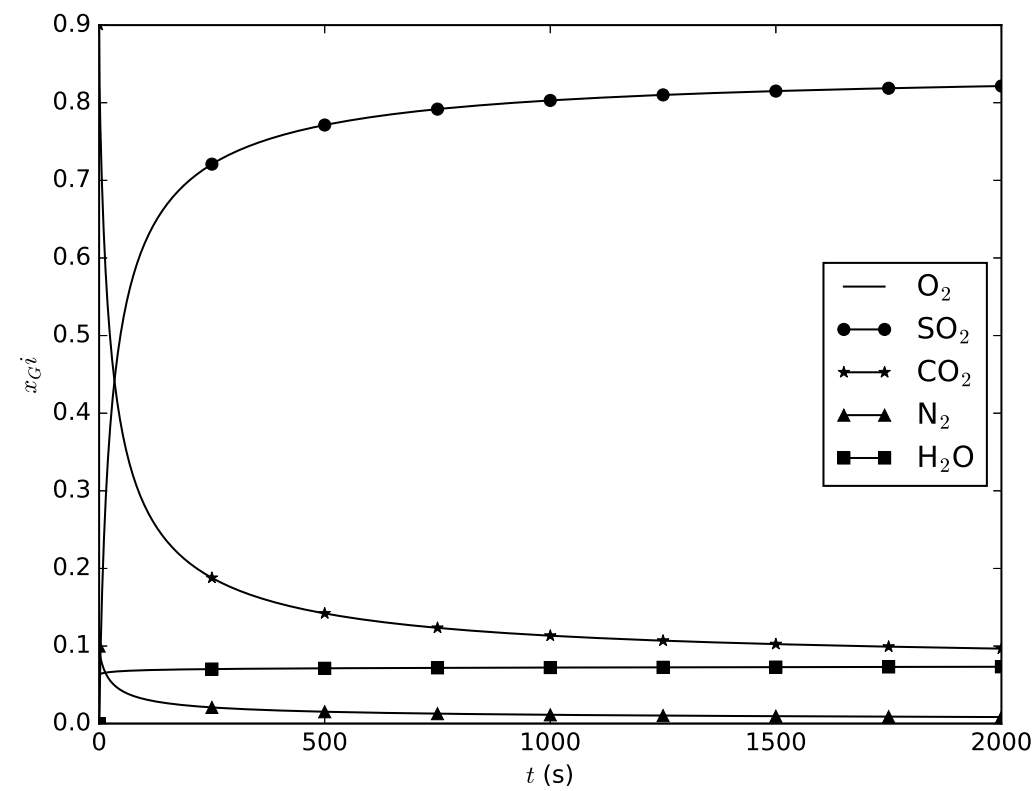

Figure 11: Molar fraction $x_{\mathrm{G}_{i}}$ of the five gas species in the bubble as a function of time obtained with the mass transfer model over the first hour for bubble on atmosphere side.

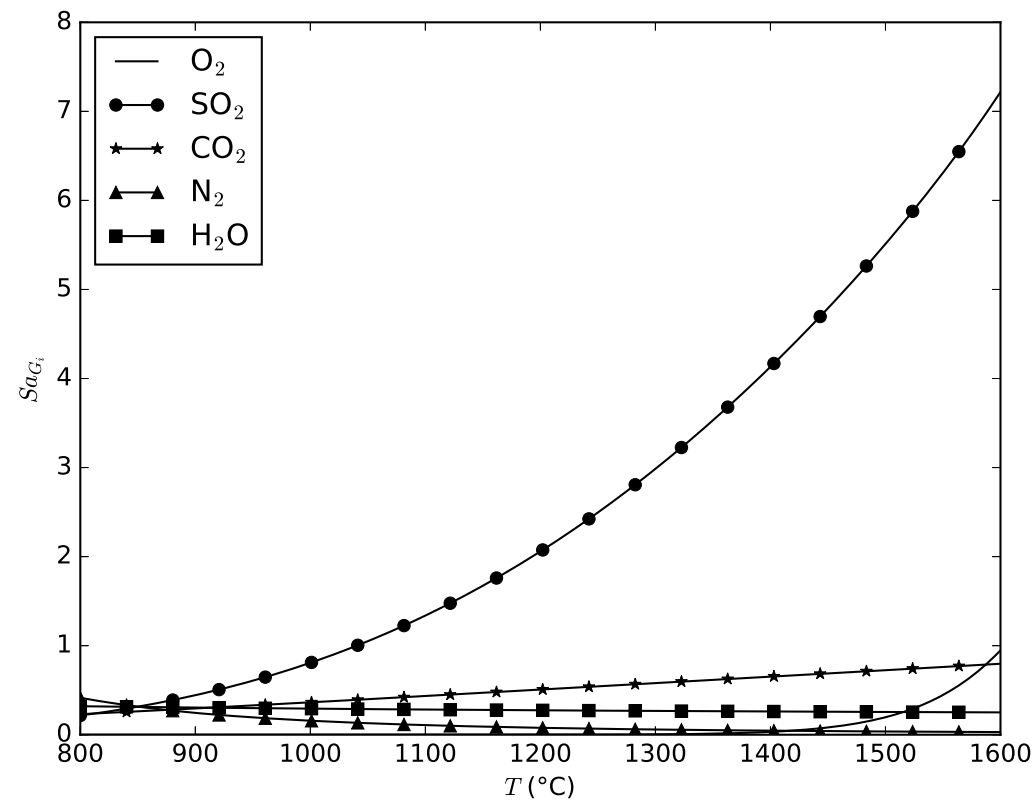

Figure 12: Saturation $S a_{\mathrm{G}_{i}}$ defined by Eq. (6) of the five gas species as a function of temperature obtained with the glass composition and redox state on tin side. 


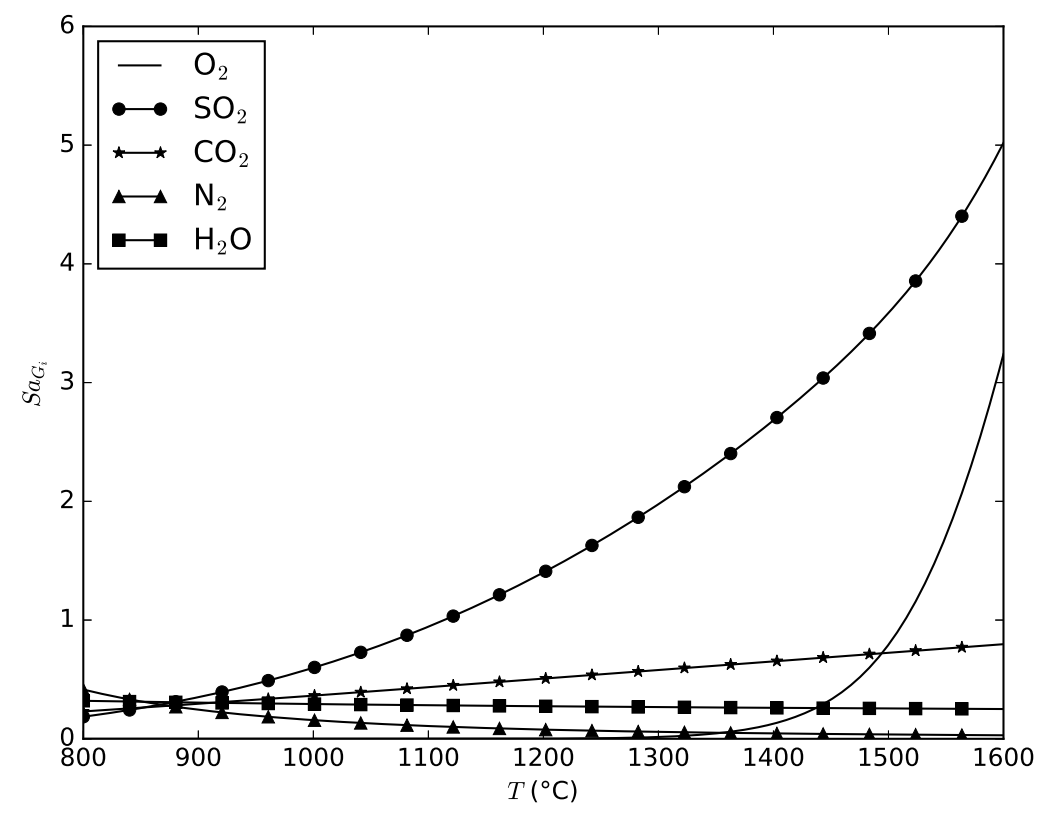

Figure 13: Saturation $S a_{\mathrm{G}_{i}}$ defined by Eq. (6) of the five gas species as a function of temperature obtained with the glass composition and redox state on atmosphere side.

the other species stay less than one over the whole range of temperature represented in Figure 12.

On atmosphere side, even if the $\mathrm{SO}_{2}$ saturation is also the most important, the amplitude is smaller than in tin side. Since the redox number is also smaller than on tin face, the amount of dissolved oxygen in the molten glass is more important. At high temperature, the $\mathrm{O}_{2}$ saturation overtakes one to reach a value larger than 3 at $1600^{\circ} \mathrm{C}$. Consequently, in this situation, both $\mathrm{SO}_{2}$ and $\mathrm{O}_{2}$ contribute to the supersaturation of molten glass.

The supersaturation $\sigma$ defined by Eq. (8) has been plotted in Figure 14 both for the two sides. At low temperature, the value of $\sigma$ is close to zero. Experimentally we observe that bubbles appear in this range of temperature while the supersaturation is close to zero. Consequently, and according to Jones et al. [11], the mode of nucleation should be due to pre-existing gas cavities at the interface between the crucible and glass samples corresponding to the mode III in the nomenclature of Jones et al. [11]. Even if the supersaturation between the two glass faces are close, $\sigma$ obtained in the reduced state on tin side is larger than in the case of oxidized glass meaning that the bubble number density is expected to be more important on tin face. Nevertheless, in absence of reliable theory to determine the bubble number density, it is impossible to control that the difference observed on supersaturation is strong enough to explain the two orders of magnitude on the bubble surface densities experimentally determined between the two sides of glass samples.

\section{Conclusion}

To investigate the bubble nucleation in re-melted glasses, float glass pieces have been melted in a silica crucible under controlled conditions. Bubble number densities as a function of the temperature and time have been recorded. The two sides of glass samples lead to two different behaviors: the bubble nucleation is intense and bubbles coalesce on tin side, whereas on atmosphere side, the nucleation is far less intense. Moreover, the bubble growth rate is also more important for isolated 


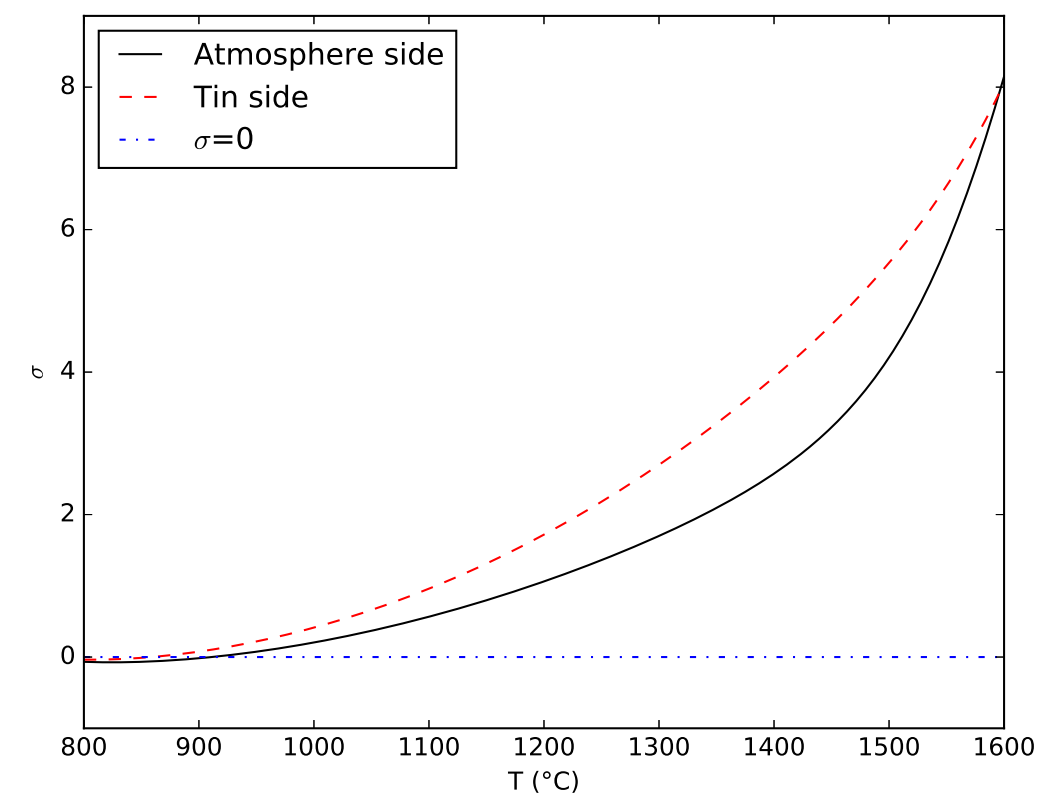

Figure 14: $\sigma$ at a function of $T\left({ }^{\circ} \mathrm{C}\right)$ on atmosphere and tin sides using the oxidation-reduction states determined from the mass transfer computation.

bubbles on tin side.

Voronoï tessellation has been used to study the bubbles spatial distribution on both sides. The difference between the two sides allows us to study the behavior of the spatial distribution with and without coalescence. The probability density function of the normalized area of Voronoï cells of a population of bubbles randomly distributed undergoing coalescence can be fitted by a singleparameter Gamma distribution. This parameter shows an exponential increase with the fraction of coalesced bubbles. Assuming the nucleation process follows a Poisson process, it is then possible to extrapolate the initial densities even when in-situ observation is not possible at the very beginning of the nucleation process.

The nucleation of bubbles on both sides of float glass during the remelting follows a Poisson process with initial densities of $d_{0}=9300 \pm 1500$ nuclei $/ \mathrm{cm}^{2}$ and $d_{0}=40$ nuclei $/ \mathrm{cm}^{2}$ on tin and atmosphere sides respectively. Consequently, the nucleation rate on tin side is more than 230 times larger than on atmosphere side. Even if the use of Voronoï tessellation has been applied to the specific case of remelting of glass, the method presented here can be used to other situations when a nucleation process happens.

To explain the main results about bubble number densities and growths, a thermodynamic and mass transfer model has been used. The main effect of tin is to reduce the existing glass. Consequently, the amount of dissolved $\mathrm{SO}_{2}$ is more important on tin side explaining the increase in growth rate. The supersaturation is also weakly larger on tin side than on atmosphere side. Nevertheless, the supersaturation is close to one at the temperature for which bubbles become visible meaning that is not required to have a high supersaturation to observe the nucleation. So, we argue that in the situation studied here, the mode of nucleation is apparently close to the mode III proposed by Jones et al. [11]. Consequently, pre-existing heterogeneities or small cavities should be present at the contact between glass samples and silica crucibles leading to the bubble nucleation. Nevertheless, experimental proof of the existence of such germs stays still to prove. 


\section{References}

[1] M. Volmer, Kinetik der phasenbildung., T. Steinkopff, 1939.

[2] J. W. P. Schmelzer, editor, Nucleation theory and applications., John Wiley \& Sons, 2006.

[3] Y. Zhang, Geochemical kinetics., Princeton University Press, Princeton, 2008.

[4] V. Talanquer and D. W. Oxtoby, "Nucleation of bubbles in binary fluids," J. Chem. Phys., 102[5] 2156-2164 (1995).

[5] S. D. Lubetkin, "Why is it much easier to nucleate gas bubbles than theory predicts?" Langmuir, 19[7] 2575-2587 (2003).

[6] Y. Qi and J. F. Klausner, "Comparison of nucleation site density for pool boiling and gas nucleation," J. Heat Transfer, 128[1] 13-20 (2006).

[7] G. Liger-Belair, "The Physics and Chemistry behind the Bubbling Properties of Champagne and Sparkling Wines: A State-of-the-Art Review," J. Agric. Food. Chem., 53[8] 2788-2802 (2005).

[8] H. M. Gonnermann and J. E. Gardner, "Homogeneous bubble nucleation in rhyolitic melt: Experiments and nonclassical theory," Geochem. Geophys. Geosyst., 14[11] 4758-4773 (2013).

[9] H. Müller-Simon, "Fining of glass melts," Rev. Mineral. Geochem., 73[1] 337-361 (2011).

[10] C. C. Mourtada-Bonnefoi and D. Laporte, "Homogeneous bubble nucleation in rhyolitic magmas: An experimental study of the effect of h2o and CO2," J. Geophys. Res., 107[B4] ECV 2-1-ECV 2-19 (2002).

[11] S. F. Jones, G. M. Evans, and K. P. Galvin, "Bubble nucleation from gas cavities - a review," Adv. Colloid Interface Sci., 80 27-50 (1999).

[12] M.-H. Chopinet, D. Lizarazu, and C. Rocanière, "L'importance des phénomènes d'oxydoréduction dans le verre," C. R. Chim., 5[12] 939-949 (2002).

[13] R. G. C. Beerkens, "Sulfate decomposition and sodium oxide activity in soda-lime-silica glass melts," J. Am. Ceram. Soc., 86 1893-1899 (2003).

[14] R. G. C. Beerkens, "Analysis of advanced and fast fining processes for glass melts"; pp. 3-24, in Advances in fusion and processing of glass III. American Ceramic Society, New York, 2003.

[15] J. Kloužek, M. Arkosiová, and L. Němec, "Redox equilibria of sulphur in glass melts," Ceram. - Silikaty, 50[3] 134-139 (2006).

[16] D.-S. Kim, B. C. Dutton, P. R. Hrma, and L. Pilon, "Effect of furnace atmosphere on e-glass foaming," J. Non-Cryst. Solids, 352[50-51] 5287-5295 (2006).

[17] T. Minami, S. Maeda, M. Higasa, and K. Kashima, "In-situ observation of bubble formation at silicon melt - silica glass interface," J. Cryst. Growth, 318[1] 196-199 (2011).

[18] M. Vernerová, P. Cincibusová, J. Kloužek, T. Maehara, and L. Němec, "Method of examination of bubble nucleation in glass melts," J. Non-Cryst. Solids, 411 59-67 (2015).

[19] T. E. Paulson, "Thermodynamic and kinetic investigation of high-temperature interactions between float glass and tin"; , Ph. D. Thesis, The Pennsylvania State University, 1998. 
[20] Q. Zhang, Z. Chen, and Z. Li, "Simulation of tin penetration in the float glass process (float glass tin penetration)," Appl. Therm. Eng., 31 1272-1278 (2011).

[21] Y. Hayashi, K. Matsumoto, and M. Kudo, "The diffusion mechanism of tin into glass governed by redox reactions during the float process," J. Non-Cryst. Solids, 282 188-196 (2001).

[22] A.-M. Flank, P. Lagarde, J. Jupille, and H. Montigaud, "Redox profile of the glass surface," J. Non-Cryst. Solids, 357[16-17] 3200-3206 (2011).

[23] M. H. Krohn, J. R. Hellmann, B. Mahieu, and C. G. Pantano, "Effect of tin-oxide on the physical properties of soda-lime-silica glass," J. Non-Cryst. Solids, 351 455-465 (2005).

[24] E. C. Ziemath, B. Z. Saggioro, and J. S. Fossa, "Physical properties of silicate glasses doped with $\mathrm{SnO}_{2}$," J. Non-Cryst. Solids, 351[52-54] 3870-3878 (2005).

[25] S. van der Walt, J. L. Schönberger, J. Nunez-Iglesias, F. Boulogne, J. D. Warner, N. Yager, E. Gouillart, T. Yu, and the scikit-image contributors, "scikit-image: image processing in Python," PeerJ, 2 e453 (2014).

[26] H. Lhuissier, D. Lohse, and X. Zhang, "Spatial organization of surface nanobubbles and its implications in their formation process," Soft Matter, 10942 (2014).

[27] C. Xu, H. Yu, S. Peng, Z. Lu, L. Lei, D. Lohse, and X. Zhang, "Collective interactions in the nucleation and growth of surface droplets," Soft Matter, 13[5] 937-944 (2017).

[28] J.-S. Ferenc and Z. Néda, "On the size distribution of poisson voronoi cells," Physica A, 385[2] 518-526 (2007).

[29] A. Okabe, B. Boots, K. Sugihara, and S. N. Chiu, Spatial tessellations : Concept and Applications of Voronoï Diagrams., Wiley, second edition, 2000.

[30] J. M. Drouffe and C. Itzykson, "Random geometry and the statistics of two-dimensional cells," Nuc. Phys. B, 235[1] 45-53 (1984).

[31] S. B. DiCenzo and G. K. Wertheim, "Monte Carlo calculation of the size distribution of supported clusters," Phys. Rev. B, 39 6792-6796 (1989).

[32] R. Monchaux and A. Cartellier, "Preferential concentration of heavy particles : A Voronoï analysis," Phys. Fluids, 22103304 (2010).

[33] I. Lifshitz and V. Slyozov, "The kinetics of precipitation from supersaturated solid solutions," J. Phys. Chem. Solids, 19[1-2] 35-50 (1961).

[34] M. V. Smoluchowski, "Versuch einer mathematischen Theorie der Koagulationskinetik kolloider Lösungen," Z. Phys. Chem., 92 129-168 (1917).

[35] E. . Villermaux, P. Marmottant, and J. Duplat, "Ligament-Mediated Spray Formation," Phys. Rev. Lett., 92[7] 074501 (2004).

[36] E. Villermaux, "Fragmentation," Annu. Rev. Fluid Mech., 39[1] 419-446 (2007).

[37] F. Pigeonneau, "Mechanism of mass transfer between a bubble initially composed of oxygen and molten glass," Int. J. Heat Mass Transfer, 54 1448-1455 (2011).

[38] B. O. Mysen and P. Richet, Silicate glasses and melts: Properties and structure., Elsevier, Amsterdam, 2005. 
[39] F. Pigeonneau, D. Martin, and O. Mario, "Shrinkage of oxygen bubble rising in a molten glass," Chem. Eng. Sci., 65 3158-3168 (2010).

[40] F. Pigeonneau, "Coupled modelling of redox reactions and glass melt fining processes," Glass Technol.: Eur. J. Glass Sci. Technol. A, 48[2] 66-72 (2007).

[41] H. Müller-Simon, "Oxygen balance in sulfur-containing glass melts," Glass Sci. Technol., 71[6] 157-165 (1998).

[42] H. Müller-Simon, "Electron exchange reactions between polyvalent elements in soda-lime-silica and sodium borate glasses," Glass Sci. Technol., 69[12] 387-395 (1996).

[43] H. Bach, F. G. K. Baucke, and D. Krause, editors, Electrochemistry of glasses and glass melts, including glass electrodes., Schott Series on Glass and Glass Ceramics, Springer, Berlin, 2001.

[44] D. Kondepudi and I. Prigogine, Modern thermodynamics: From heat engines to dissipative structures., John Wiley \& Sons, New York, 2nd edition, 2015.

[45] M. S. Plesset and A. Prosperetti, "Bubble dynamics and cavitation," Annu. Rev. Fluid Mech., 9[1] 145-185 (1977). 